\title{
A DESCONSTRUÇÃO DERRIDIANA E O PROCESSO CRIATIVO DE PINA BAUSCH
}

\author{
THE DERRIDA'S DECONSTRUCTION AND THE CREATIVE PROCESS \\ OF PINA BAUSCH
}

\section{LA DECONSTRUCCIÓN DE DERRIDA Y EL PROCESO CREATIVO DE PINA BAUSCH}

\section{Marcia Furlan de Almeida ${ }^{1}$}

\section{RESUMO}

Para Jacques Derrida, o pensamento metafísico ocidental se encontra alicerçado em uma lógica dual cujos polos se contrapõem e se excluem. Sua filosofia, por meio da desconstrução, busca abalar as estruturas desse pensamento - denominado por ele - logocêntrico. Para tal intento, suas proposições nos remetem a movimentos constantes na busca por significações sempre proteladas no jogo das diferenças e trazem em seu bojo a experiência da alteridade. Pina Bausch, através de suas peças, ao expor continuamente o corpo com suas potências e vulnerabilidades ao outro, convida-nos a adentrar em um jogo das diferenças. Em sua linguagem cênica, o 'outro' se coloca como condição sine qua non nesse jogo de múltiplos significados que finda por produzir e afirmar diferenças. Este artigo busca possíveis atravessamentos entre o movimento da desconstrução do filósofo Jacques Derrida e o processo criativo da bailarina e coreógrafa Pina Bausch no 'Wuppertal Tanztheater', a desestabilização da dualidade ao desfazer a fixidez da essência e propiciar significações outras.

PALAVRAS-CHAVE: Derrida. Desconstrução. Pina Bausch. Processo criativo.

\section{ABSTRACT}

To Jacques Derrida, the western metaphysical thought is rooted in a dual logic whose poles are opposed and mutually exclusive. His philosophy through deconstruction seeks to shake the structures of this thought named by him - logocentric. For this purpose, its propositions bring us to the constant movements in the search for meanings always delayed in the game of differences, and brings in its core the experience of otherness. Pina Bausch, through its spectacles, to continuously expose the body with its powers and vulnerabilities to the other, invites us to enter the game of differences. In its scenic language, the 'other' arises as a sine qua non in this game of multiple meanings that ended up producing and affirm differences. This article aims to present a possible crossings between the movement of the deconstruction of the philosopher Jacques Derrida and the creative process of the dancer and choreographer Pina Bausch in 'Tanztheater Wuppertal', in the search for destabilization of duality to undo the fixity of the essence and provide other meanings.

KEYWORDS: Derrida. Deconstruction. Pina Bausch. Creative process.

\footnotetext{
${ }^{1}$ Doutoranda do Programa de Pós-Graduação em Educação - Faculdade de Educação - Universidade Estadual de Campinas (UNICAMP) - Campinas, SP. Brasil. Professora de Educação Básica - Secretaria de Educação do Estado de Sergipe. E-mail: marciafurlan@gmail.com

Submetido em: 30/11/2016 - Aceito em: 15/07/2017
}

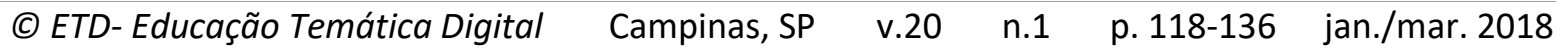




\section{RESUMEN}

Para Jacques Derrida, el pensamiento metafísico occidental tiene sus raíces en una lógica dual cuyos polos son opuestos y mutuamente excluyentes. Su filosofía a través de la deconstrucción, intenta sacudir las estructuras de este pensamiento - por él denominado - logocéntrico. Para tal propósito, sus proposiciones nos llevan a los movimientos constantes en la búsqueda de significaciones siempre aplazadas en el juego de las diferencias, y traen consigo la experiencia de la alteridad. Pina Bausch, a través de sus piezas, al exponer continuamente el cuerpo con sus potencias y vulnerabilidades al otro, nos invita a entrar en el juego de las diferencias. En su lenguaje escénico, el "otro" surge como una condición sine qua non en este juego de múltiples significados que termina produciendo y afirmando las diferencias. Este artículo busca los posibles atravesamientos entre el movimiento de la deconstrucción del filósofo Jacques Derrida y el proceso creativo de la bailarina y coreógrafa Pina Bausch en el 'Tanztheater Wuppertal', en la búsqueda de la desestabilización de la dualidad al deshacer la fijeza de la esencia y proporcionar significaciones otras.

PALABRAS CLAVE: Derrida. Deconstrucción. Pina Bausch. Proceso creativo.

\section{CENA INTRODUTÓRIA}

Silêncio... pouca luz... aos poucos, os olhos se acostumam a enxergar na penumbra... e então vemos alguns painéis de vidro e uma porta giratória ao fundo, o palco repleto de mesas e cadeiras escuras, dispostas de maneira que evidenciam a presença de corpos ausentes... 'Café Müller',' momentos de encontros, de separação, de reencontros, aproximações e distanciamentos de corpos. Tensões em corpos que se desprendem e prenunciam a mortalidade do amor e, que no ato da despedida, anunciam a saudação ao porvir.

Contrastes de sensações nos surpreendem através dos corpos dos bailarinos e bailarinas, deslocando-se por meio de movimentos bruscos e suaves, contínuos e fragmentados...

A bailarina, coreógrafa e diretora alemã Pina Bausch contribuiu para a inscrição da dança-teatro na contemporaneidade. Suas obras ${ }^{3}$ nos confrontam com a dualidade entre os polos por meio de gestos e falas. As fronteiras entre as diversas artes e suas linguagens são permanentemente tensionadas, porque não há uma forma estética, na qual se apoiar, ao se afastar das certezas de saberes e métodos estabelecidos.

\footnotetext{
${ }^{2}$ Estreou em 20 de maio de 1978 no Opera House - Wuppertal e no Brasil em 1980. De forma minimalista, seis dançarinos e dançarinas, incluindo Pina Bausch, expõem as contradições humanas, seus desejos, prazeres e frustações. 'Café Müller'apresenta uma Alemanha pós-guerra, memórias de infância em que Pina observava as pessoas por debaixo das cadeiras do bistrô de seu pai.

${ }^{3}$ Sua obra, composta por mais de 40peças criadas para o 'Tanztheater Wuppertal' e apresentadas em diversos países entre 1974 a 2009, inclui também um filme com sua direção 'O Lamento da Imperatriz' (1990), e participação no filme de Federico Fellini interpretando a 'Principessa Lherimia'em 'La nave va' (1982) e no 'Fale com Ela' (2002) filme de Pedro Almodóvar, participa com excertos das peças'Cafe Müller'e‘Mazurca Fogo'. Realizou algumas peças para televisão a exemplo de 'Orfeu e Eurídice' (1980), e seu trabalho foi tema de vários documentários na televisão e no cinema.
}

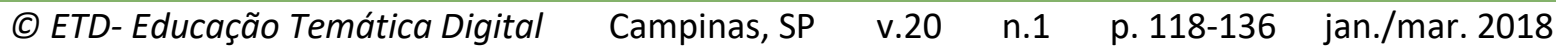


Neste sentido, é que em Pina Bausch um gesto sempre remete a outros gestos, e, por meio de atos transgressivos, suas criações tensionam as fronteiras dos campos pretensamente tão bem demarcados - das atividades humanas. Como observa Gil (2004), não se separa o que é dança e o que é teatro, de maneira que o teatro adentra a dança e vice-versa. Pois, findam por construir uma outra prática que se institui pela coexistência de performances corporais diversas na linguagem cênica.

Em suas criações, as transgressões desconstroem a polarização dos campos de saber-fazer, e os limites se encontram em permanente movimento, lançando-se a um não lugar, que não é um fora e nem um dentro. Assim, os movimentos que Pina cria desconstroem a unidade alicerçada no paradigma da totalidade ao realçar as descontinuidades e as fissuras de discursos. E, dessa forma, corrobora a afirmativa de Jacques Derrida (2012) de que a desconstrução mais efetiva é a que trata de discursos não escritos, a exemplo das práticas artísticas. Destarte, segundo o filósofo português José Gil (2004, p.178-179), em suas criações, Pina Bausch:

[...] não se limita a atualizar a géstica do pensamento e das emoções que envolve qualquer situação. As improvisações a propósito de um tema podem provocar associações de palavras que o gesto transporta consigo e que remetem eventualmente para outros gestos, outras palavras e outros pensamentos [...] não utiliza, pois, de uma só maneira a relação palavra-gesto; sobretudo, porque não constrói um tipo apenas de gestos. [...] Os seus gestos podem assim parodiar os do ballet clássico ou reproduzir uma cena "real" de violência entre os dois membros de um par; podem sugerir os gestos do circo, bem como dos jogos infantis; etc. $O$ enxerto, a associação, o cruzamento, a sobreposição incessante de inumeráveis tipos de gestos codificados e conhecidos tornam-se apêndices, variações e prolongamentos de um outro gênero de gestos [...].

Tais deslocamentos avivam uma atitude desconstrucionista em suas criações ao levar para o palco gestos cotidianos presentes em diversas práticas e, que através da repetição e de remetimentos contínuos, findam por explodir significados únicos de movimentos padronizados. Pina se nega amoldar seus trabalhos a conceitos determinados apriori - conforme disposto no decorrer deste artigo - reafirmando assim, ao nosso olhar, as proposições derridianas para com os textos,no qual o significado nunca é fixo e estável, em vez disso, a significação se encontra num movimento permanente de busca do 'significante do significante'. Dessa maneira, os remetimentos constantes acabam por impedir que o significante esteja presente em si mesmo, passando então a se constituir a partir dos rastros de outros. Este é o jogo das diferenças ou différance como é denominado por Derrida (2004a); meio pelo qual se produz as diferenças e que traz em seu bojo a experiência da alteridade.

Pina nos convida a adentrar o jogo das diferenças ao expor continuamente o corpo com suas potências e vulnerabilidades ao outro. Logo, o corpo se encontra exposto às marcas indeléveis do outro, à sua presença espectral. Em sua linguagem cênica, o 'outro' se

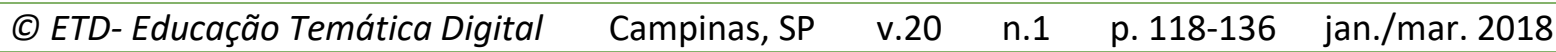


coloca como condição sine qua non nesse jogo de múltiplos significados que finda por produzir e afirmar diferenças. Contudo, afirma-las, é ao mesmo tempo, afirmar também a possibilidade de diferir, de mudanças, de surgimento do novo. Assim, Pina Bausch coloca em cena diferentes leituras dos movimentos.

\section{TRANSGRESSÃO... UM MOVIMENTO CONSTANTE}

Vale observar que Pina Bausch iniciou seus estudos pela dança clássica e, ao incluí-la em seu processo criativo, recorre à sua herança. Entretanto o faz sem apelar ao virtuosismo técnico, mas, contestando suas formas prontas que buscam conformar corpos. Afinal de contas, como desconstruir uma gramática sem acolher seus conceitos? Sem abalar as estruturas que a edificam? Nesta altura, é pertinente notar que Derrida, por acreditar que nenhum pensamento evada à metafísica que o alicerça, denota uma atitude de respeito aos textos da tradição. Ainda, que tal atitude de respeito não implique necessariamente em concordância, mas a possibilidade de inquirir, de contradizer (ALMEIDA, 2014), a ponto de forçar esses textos enunciarem algo absolutamente diferente do que eles haviam enunciado, e chegar, conforme propõe o filósofo, a "[...] desconstruir uma lógica do texto que veio antes de mim" (2004b, p. 337).

Em concordância a tais entendimentos é que os corpos dos bailarinos e bailarinas de sua companhia 'Tanzteather Wuppertal' ${ }^{4}$ passam por constantes desafios nesse processo de desmonte das amarras da tradição. Ao se empenhar em romper com a ideia de origem, com a noção de algo dado desde sempre, seu trabalho ao mesmo tempo que transgride os paradigmas da tradição artística, amplia consideravelmente as possibilidades de movimento e "vai além da técnica do repertório dos bailarinos clássicos e mesmo modernos", como observa Cypriano (2005, p.29). Pina reafirma: “Não gosto de categorias, quero sempre escapar a isso" (apud GUERREIRO, 2007, p.62).

Por transgredir as normas da tradição, seu trabalho foi rejeitado no início, tanto pelos bailarinos e bailarinas, que manifestavam a vontade de se afastarem da companhia por não aceitarem as formas empregadas por Pina na criação das peças, como pelo público. Em relação aos bailarinos, Pina revela que chegou a sentir medo deles, porque procurava fazer-se entender, mas não conseguia e, devido às dificuldades encontradas, teve vontade de parar com o trabalho (CYPRIANO, 2005). Quanto ao público, habituado a prestigiar os espetáculos de ballet clássico, que por meio de seu código inalterável de movimentos se

\footnotetext{
${ }^{4}$ Ao completar quinze anos Pina Bausch ingressou no curso de dança na 'Folkwang Hochschule'em EssenAlemanha. Seu mestre, Kurt Jooss, foi aluno de Rudolf Von Laban, precursor da dança-teatro. Pina conclui sua formação em Dança e em Pedagogia da Dança em 1958 e no ano seguinte vai para Nova York com bolsa de estudos. Retorna para a Alemanha em 1962 como solista do 'Folkwang Ballet'a convite de Jooss. Em 1973 assume a direção da companhia de dança 'Wuppertal Ballet' que passa a chamar 'Tanztheater Wuppertal'.
}

(C) ETD- Educação Temática Digital Campinas, SP $\quad$ v.20 $\quad$ n.1 $\quad$ p. 118-136 jan./mar. 2018


mostrava indiferente à história e à significação humana (GARAUDY, 1980), talvez fosse tocado de maneira incômoda ao ser confrontado com os conflitos humanos que Pina apresentava no palco; levando grande parte da plateia a expressar sua indignação ao vaiar e até mesmo abandonar o teatro durante as apresentações.

Já em 2007, com seu trabalho reconhecido mundialmente, Pina, em uma entrevista à Revista Obscena no Teatro Camões em Lisboa, assume a importância de aprender a técnica, mas em um ato continuum, esquecê-la e assim, ser capaz de ir além dela e produzir momentos de poesia, somente então, surgirá a beleza. Nesta mesma entrevista - à jornalista e crítica para as Artes do espetáculo, Mônica Guerreiro (2007) -, ao ser indagada acerca das características dos bailarinos de sua companhia, Pina relata que não há um padrão que oriente sua escolha e por isso todos eles são bastante diferentes, alguns jovens, outros mais velhos, de distintas estaturas, sendo alguns fortes, outros magros e de várias nacionalidades.

Seu encantamento pelas diferenças é o mote propulsor desse encontro e o que a estimula a realizar um trabalho em conjunto. Tal assertiva nos remete a Sílvio Gallo (2008, p. 1), ao afirmar que a "educação é um encontro de singularidades" e acrescentar que na perspectiva de Espinosa podemos dizer que "há bons encontros" capazes de aumentar a "potência do pensar e agir". É na esteira desse pensamento que percebemos a sensibilidade de Pina Bausch ao lidar com as singularidades de cada integrante de sua companhia, por exemplo, quando explica que alguns bailarinos são lentos e que prosseguem devagar, todavia alcançam lugares formidáveis. Já outros conseguem aprender rapidamente, mas não conseguem avançar. E complementa "[...] são todos tão diferentes que também não é possível falar-se em 'melhor'. Têm qualidades muito diversas, não são sequer comparáveis" (GUERREIRO, 2007, p.67). Com isso, seus 'pensares e agires' significam o outro como outro, e as diferenças em seu processo de criação são significadas continuamente no coletivo porque não se pode pensar pelo outro, criar para o outro, senão pensar e criar com o outro.

Sendo assim, a fim de desenvolver um processo criativo coletivo que contemple as singularidades, Pina Bausch permite que seu ouvido acolha as falas de cada um e de cada uma, e colocando várias questões a cada ensaio, centenas delas durante todo o trabalho. Ela exemplifica em uma entrevista: "Durante muito tempo vou fazendo perguntas atrás de perguntas. Ponho-os loucos [risos]" (CANELAS, 2003). Os questionamentos partem das experiências dos criadores-bailarinos e findam por suscitar lembranças agradáveis ou dolorosas, fantasias, desejos, uma infinidade de sentimentos que são expressas através de palavras, movimentos ou até mesmo silêncios. No processo criativo coletivo, os criadoresbailarinos precisam necessariamente sentir de forma genuína e não representar o que é proposto pela coreógrafa.

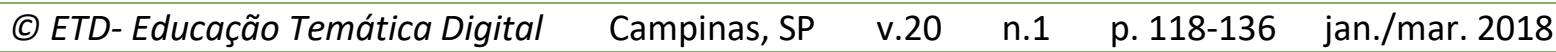


A esse respeito, Raimund Hogle, dramaturgo, que trabalhou com Pina, durante dez anos, conta que no decorrer de uma conversa após um ensaio, ela comenta com um de seus criadores-bailarinos ${ }^{5}$ : "Eu acho ótimo que cada peça tenha algo de vocês, um pedaço de suas vidas [...] Cada um deve poder ser assim como quer ou se desenvolveu" (1989, p.28). Como consequência dessa elaboração, Cypriano aponta que o desdobramento dessa estratégia implica em uma particularidade na obra bauscheana, na qual os bailarinos retratam a si mesmos. Assim, "Nos espetáculos, são chamados pelo nome, mostram fotos antigas, contam experiências vividas" (2005, p.29), tecendo uma trama onde os fios da realidade e da ficção se mesclam.

Esta forma inusitada de seu processo de criação se entrecruza a partir da década de 1980, com períodos de residência da 'Tanztheater Wuppertal' em cidades de vários países, nas quais, Pina e todos os integrantes da companhia usavam todo o tempo que passavam nas urbes para observar as pessoas, os modos como se relacionavam em diversos espaços da cidade e buscavam ver de perspectivas diversas os elementos da vida diária. Não se pretendia representar os aspectos culturais de um país, mas deixar se envolver pela cidade, afinal como ela própria advertia "Cidades são como pessoas, é preciso se apaixonar para descobri-las" (KATZ, 2000, on-line).

Em 1985, a convite do diretor artístico do 'Teatro Argentina', em Roma, Pina realizou a sua primeira residência artística, cujo resultado foi a peça 'Viktor' que estreou em 1986. Em continuidade, cidades de tantos países além da Itália, foram temas de suas criações: Turquia 'Nefés', China 'Der Fensterputzer'[O limpador de vidraças], Portugal 'Masurca Fogo', Hungria 'Wiesenland' [Terra de Prados], Índia 'Bamboo Blues', Coreia do Sul 'RoughCut'[Corte bruto], Japão 'Ten Chi'[Céu e terra], Chile '... como el musguito en la piedra, ay si, si, si...', entre outras produções.

Quando Pina foi convidada pela segunda vez, para realizar outra residência em Roma, após doze anos, revela que ficou indecisa, pois se questionava sobre as possibilidades de se apaixonar de uma outra forma pela mesma cidade. Findou aceitando e criando sua peça 'O Dido', por acreditar que não há somente duas formas de vivenciar os lugares, justamente porque eles são como as pessoas, o processo para as conhecer é inesgotável. É interessante pontuar a estreita aproximação da bailarina com o filósofo ao não permitir ser capturada pelo "[...] destino implacável que enclausura tudo na vida ao número 2" (DERRIDA, 1982, p.76); ele assinala as inúmeras possibilidades que se mostram quando se ousa ir além da lógica dual instaurada pela metafísica ocidental. Com isso, é nos constantes

\footnotetext{
${ }^{5}$ Considerando este processo coletivo de criação é que Cássia Navas -Professora do Instituto de Artes-Unicamp - emprega o termo 'criadores-bailarinos' para se referir aos integrantes do 'Tanzteather Wuppertal'(2008); compreendendo a importância do processo de criação coletiva desenvolvido por Pina Bausch, este termo é utilizado neste artigo sempre que nos referirmos aos bailarinos e bailarinas da Companhia.
}

(C) ETD- Educação Temática Digital Campinas, SP $\quad$ v.20 $\quad$ n.1 $\quad$ p. 118-136 jan./mar. 2018


deslocamentos da différance, ao se lançar infindavelmente através do 'rastro do rastro do rastro', que a significação não é fixa nem estável, mas sempre protelada.

As implicações, a partir deste pensamento da desconstrução derridiana, sobre os modos outros de Pina criar suas peças se apresenta em sua analogia a respeito das cidades. Diz ela:

As cidades são como cebolas, feitas de camadas que se ligam e que podem ser abordadas de vários pontos distintos. Mesmo quando se permanece no mesmo anel dessa cebola, sempre se vê aquilo que fica ao redor a partir de um lugar diferente porque, como o ser humano está sempre se modificando, isso permite que quando se volta ao mesmo lugar, ele não seja mais o mesmo (KATZ, 2000, online).

$E$, dando seguimento às residências nas cidades, Pina Bausch revela à jornalista Lucinda Canelas (2003), "Andei a 'comer' imagens e cheiros que não conhecia, nos terreiros de magia africana ou nas noites de forró (...) Em 'Água' há um pouco de tudo isto", referindo-se à peça criada tendo como inspiração o Brasil. Com músicas de Tom Jobim, Tom Waits, Baden Powell, Ike Quebec, Caetano Veloso, Gilberto Gil, P. J. Harvey, Tom Zé, Susana Baca, Carlinhos Brown, entre outros, os vinte bailarinos do 'Tanztheater Wuppertal' criam imagens e desenvolvem situações advindas de suas andanças pelas cidades de São Paulo e de Salvador.

Em suas paragens nas feiras, mercados, casas de pagode, favelas, Pina está sempre a observar as pessoas, que são o mote de suas inquietações. O 'outro' sempre é a matéria prima de seu trabalho, independentemente da cidade onde estivesse, ela sabia que de uma forma ou de outra, estamos constantemente expostos uns aos outros. Talvez, a potência de suas criações advenha justamente das transgressões, já que elas - conforme o entendimento de Derrida (2001), requerem que limites estejam incessantemente em movimento.

\section{CORPO QUE NOS TOCA...}

A concepção de corpo predominantemente encontrada nas práticas artísticas é de um corpo que é tomado em suas singularidades com base em valores renascentistas, mas também agregando um intenso empreendimento da modernidade sobre as fronteiras de si, repercutindo entre outras coisas, no autocontrole de gestos (CORBIN, et al., 2008). Segundo tal entendimento, é com frequência na dança, que o corpo é considerado como objeto a ser adestrado através de um treinamento rigoroso e sempre em busca de um virtuosismo técnico e de formas perfeitas.

Em contraposição a tais verdades instituídas, Pina rompe coma estética corporal vigente ao escolher seus criadores-bailarinos considerando a capacidade de se atreverem e

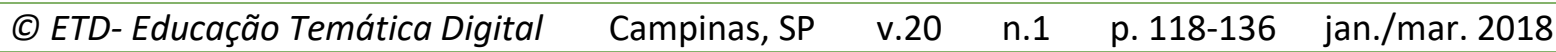


se exporem às estéticas outras. E assim esclarece, "não me parece lógico avaliar bailarinos por padrões do concurso de Miss Universo. Personalidade conta muito mais do que balança e fita métrica" (PORTINARI, 1985, p.31). É muito interessante reparar que o corpo que Pina coloca no palco não é um corpo esculpido pela técnica, que beira à perfeição, à divinização, e, portanto, inacessível; em vez disso, é um corpo ordinário, que encontramos no dia a dia nas diversas práticas!

Cabe destacar que Pina coloca no palco não somente os corpos de bailarinos profissionais. Sua peça 'Kontakthof'[Pátio de Encontros ou Pátio de Contatos] foi criada com os bailarinos do 'Tanztheater Wuppertal', em 1978, e trata principalmente dos meandros da relação entre homens e mulheres, tema recorrente em suas criações. Como na maior parte de suas peças, os antagonismos entre o feminino e masculino são colocados repetidas vezes, de tal maneira que a partir dos relatos de seus criadores-bailarinos, faz emergir as contradições, as angústias, os conflitos e os inevitáveis enfrentamentos.

Em 2000, no palco do 'Opera House', em Wuppertal,estreia 'Kontakthof mit Damen und Herren ab' 65'; peça criada em 1978, mas dessa vez, são homens e mulheres com mais de 65 anos de idade - que simplesmente gostavam de dançar - que são levados ao palco. Se para eles também, não importava 'o como, mas o que os moviam', já que não se sentiam envelhecidos - por que não aceitar o convite desafiador para trabalharem sob a direção de Pina Baucsh? Então, enfrentaram desafios, expuseram seus corpos, contaram suas histórias. Em alguns momentos provocando um desassossego, como a cena em que após todos os integrantes avançarem no palco em direção à plateia, executando a mesma sequência de movimentos, mantendo-se compenetrados, indiferentes ao profundo silêncio ou às súbitas risadas descontroladas de uma mulher que cai no chão. Assim, alheios ao que se passa na mesma cena, viram-se de costas e retornam ao fundo do palco, continuamente a executar os mesmos movimentos, como que automatizados. Então, sentam-se nas cadeiras, um ao lado do outro, e de repente um senhor aparece segurando um rato e correndo pelo palco em direção a uma senhora que apavorada dispara em sentido oposto acompanhada pelos demais; o que ocasiona risos na plateia. Essa cena, que contrapõe a coragem do homem à fragilidade da mulher, repete-se várias vezes no decorrer da peça, mas a cada vez, algo muda, e a reação da mulher será distinta.

Nesse contínuo jogo das diferenças, homens e mulheres com mais de 65 anos se mostraram surpresos ao perceber que ainda eram capazes de aprender coisas novas e superar limites, significando de inúmeras maneiras o seu próprio viver. Assim, contagiaram o público, e a previsão de realizar somente duas apresentações se estendeu a outras cidades da Alemanha, bem como a outros países europeus. 
Em 2008, uma terceira montagem de 'Kontakthof', leva ao palco cerca de quarenta adolescentes de 14 a 18 anos que não tinham nenhuma experiência profissional com a dança. Os ensaios eram realizados aos sábados sob a orientação das bailarinas Josephine Ann Endicott e Bénédicte Bille, ambas participantes da criação da peça em 1978 no 'Tanztheater Wuppertal.'

Foram realizados registros audiovisuais das três montagens, em momentos distintos e com finalidades diversas. Dessa maneira, um trecho da primeira montagem de 'Kohntakthof',em 1978, integra o filme 'Un jour Pina m'a demandé', sob a direção de Chantal Akerman em 1983. Na segunda montagem, em 2000, foi produzido um filme documentário 'Kontakthof Mit Damen und Heren ab 65' com direção de Lilo Mangelsdorff, que acompanhou as diversas etapas da produção da peça. E, na terceira montagem em 2008, foi elaborado o documentário 'Tanzträume' [Sonhos em Movimentos] dirigido por Anne Linsel e Rainer Hoffman, as duas presenciaram todo o transcurso dos adolescentes nos ensaios e também a repercussão desse trabalho em suas vidas.

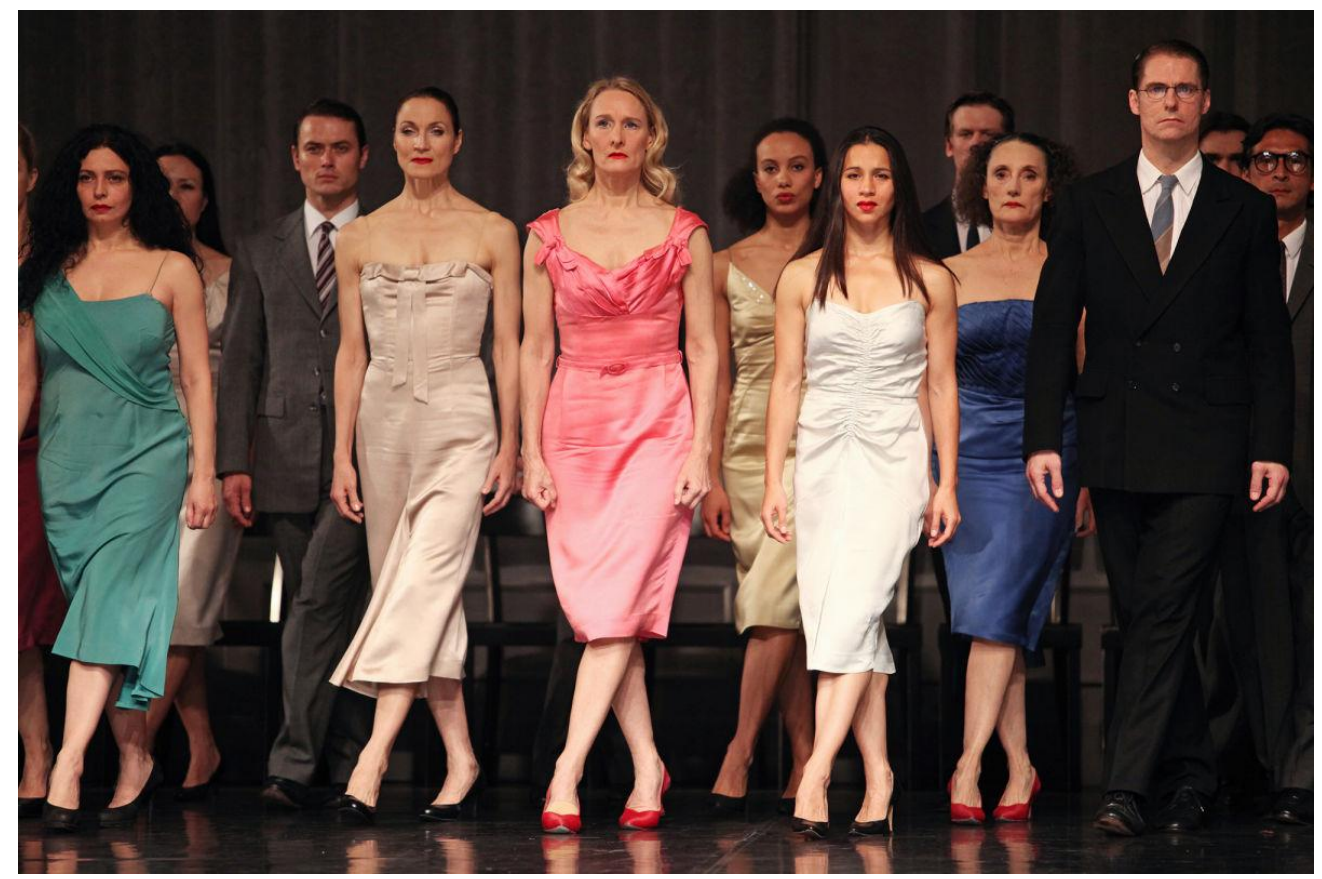

Imagem 1.'Kohntakthof'

Foto: Julieta Cevantes. 


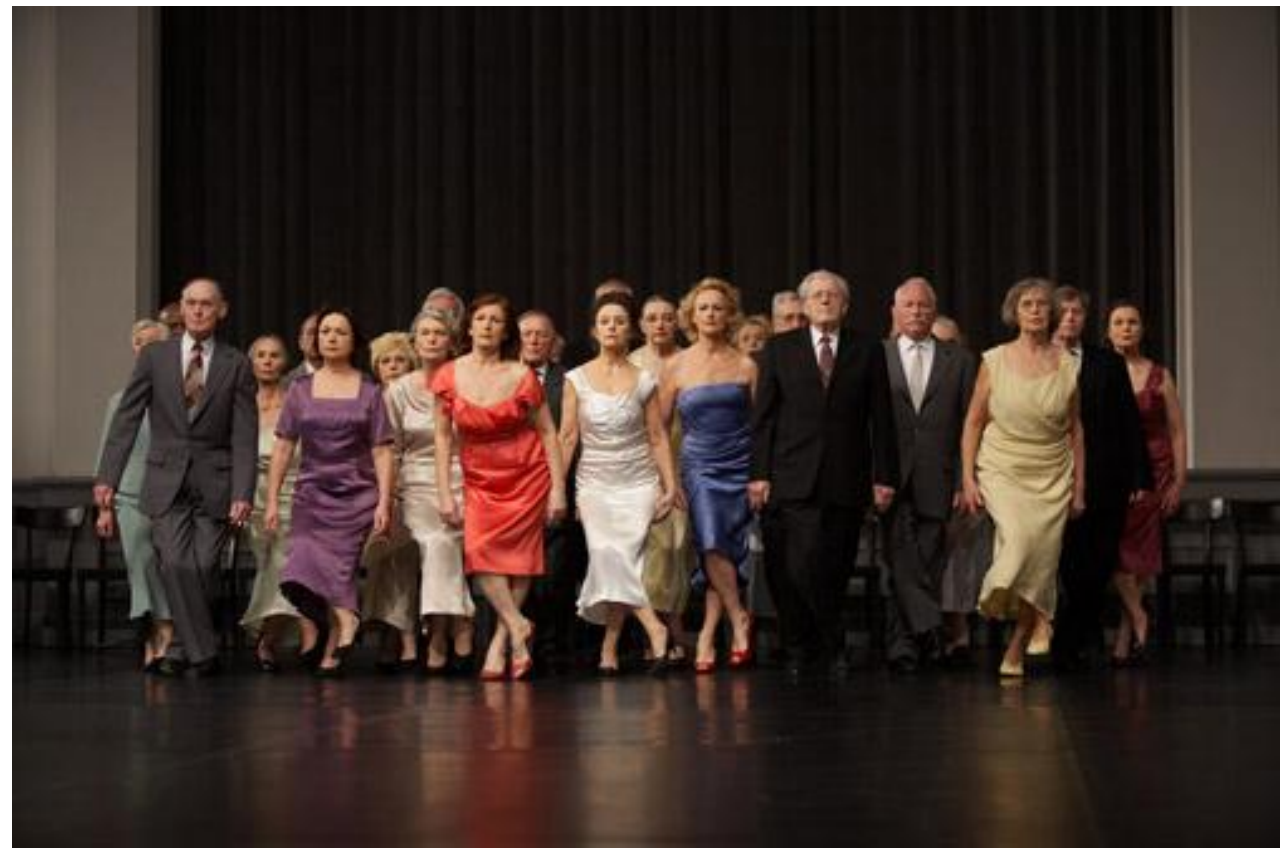

Imagem 2.'Kontakthof mit Damen und Herren ab' 65' Foto: Laszlo Szito.

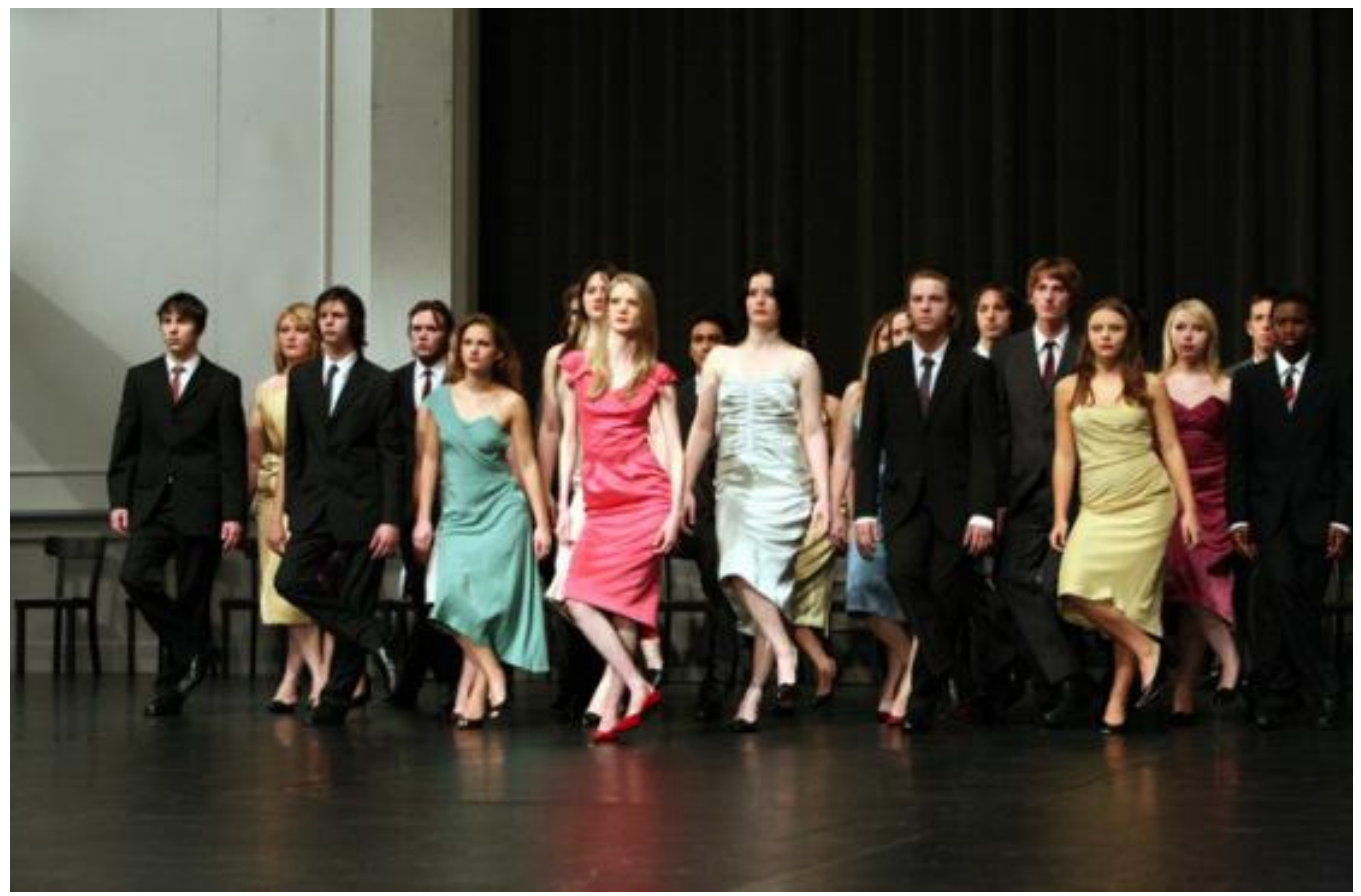

Imagem 3. 'Kontakthof - Sonhos em Movimento' Foto: Ursula Kaufmann. 
Se, no início, os adolescentes se mostravam inseguros, conforme registros dos depoimentos deles no filme 'Sonhos em Movimento', à exemplo da fala de uma garota "Ficamos nervosos, imaginando se está bom ou não", e de uma outra "Talvez eu seja diferente, sou reservada", a medida em que o trabalho se desenvolvia foi sendo criado, concomitantemente, um espaço para que expusessem seus sentimentos, medos, desejos e sonhos.

Pina Bausch comumente dizia: "Eu não investigo como as pessoas se movem, mas o que as move" (CYPRIANO, 2005, p. 27), assim ao participarem do processo criativo em suas peças, os bailarinos e bailarinas do 'Tanztheater Wuppertal', as senhoras e senhores e os adolescentes, cada um, cada uma, vivencia uma experiência de algo evidentemente, mas principalmente vivencia a experiência de sua 'própria transformação'. Com maestria, Jorge Larrosa esclarece que experiência "é o que nos passa, o que nos acontece, o que nos toca. Não o que se passa, não o que acontece, ou o que toca" (2002, p. 21). Tal qual um 'território de passagem', no qual o potencial transformador da experiência deixa seus vestígios (LARROSA, 2011), é que um adolescente em 'Sonhos em Movimento' revela “Fiz amizade com pessoas que eu iria ignorar se visse na rua". São modificações nos modos de se relacionar com o 'outro', nos modos de estar no mundo.

\section{REPETIÇÃO E DIFERENÇA}

Outro elemento constante em suas montagens é a repetição de gestos. Os permanentes remetimentos de gestos nas coreografias findam por desfazer a ilusão de preexistência de sentidos e de origem. Dessa forma, por se encontrar no jogo de significações, em que a significação é sempre protelada e a presença constantemente adiada, é que suas apresentações não são postas em cena como um trabalho finalizado, no qual se alcançou a perfeição técnica. A esse respeito Bausch declara: "A dança deve ter outra razão além de simples técnica e perícia" (BENTIVOGLIO, 1994apud CYPRIANO, 2005, p.27).

Com tais questionamentos, Pina mostra em suas peças, um processo em permanente construção, já que há sempre um rastro, um deslocamento por vir. Desse modo, no palco, não são postos juízos de valor, é o expectador que buscará suas respostas, suas próprias significações; sempre se posicionando nos contextos e aos textos de forma idiossincrática. Com esse entendimento, a coreógrafa nunca escreveu uma sinopse ou uma história para seus espetáculos, porque segundo ela "nunca há só uma história, são muitas pequenas histórias que podem ser desenvolvidas de maneiras diferentes" (GUERREIRO, 2007, p.69). Sob esse prisma, é que em suas narrativas, as cenas vão se repetindo, em diferentes momentos e em cada um deles com pequenas diferenças, e a cada repetição é possível reconhecer algo já trilhado, mas que traz consigo novos desafios.

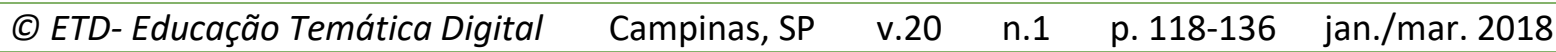


Assim é que, através de permanente repetição de gestos em seus trabalhos, os criadores-bailarinos findam por desfazer a fixidez da essência, deflagrando uma multiplicidade de significados. Desse modo, gestos se repetem e trazem o que foi imposto pela tradição, repetem-se e divergem, repetem-se e desestabilizam, repetem-se e possibilitam o desvio, repetem-se e criam o novo (ALMEIDA, 2014).

Mas, por que o espanto? Caríssimo leitor, caríssima leitora... a repetição do mesmo e o surgimento do novo lhe parece paradoxal?

Ao responder a esse questionamento em uma entrevista a Antoine Spire, publicada pelo 'Le Monde de l'éducation', em setembro de 2000, Derrida assegura que não há antagonismo entre a repetição e o novo, visto que a diferença continuamente fará com que a repetição se desvie. Movimento denominado por ele de iterabilidade, através do qual de maneira imprevisível, o singular surge através de repetições (DERRIDA, 2004b), inevitavelmente...

Por entre as intensidades de corpos desfazendo o uno, desorganizando o previsível ao repetir gestos e palavras é que Pina Bausch busca incansavelmente através da criação de movimentos, tornar possível a multiplicidade de significações, conforme ela mesma comenta a respeito de suas montagens: "O que acho que está bem é uma pessoa poder ver de certa maneira e outra de uma maneira completamente diferente" (HOGHE, 1987 apud GIL, 2004, p.171). Com essas preocupações, uma inesgotável produção de significações é colocada em cena, até mesmo gestos cotidianos que,

[...] são trazidos ao palco e, pela repetição, tornam-se abstratos, não necessariamente conectados com suas funções diárias [...] as exaustivas repetições provocam sentimentos e experiências nos dançarinos e na plateia. Significados são transitórios, emergindo, dissolvendo, e sofrendo mutações em meio a repetições. [...] constantemente fragmentam e separam os significados de suas formas originais. Conteúdos e significados são constantemente descartados e desafiados [...] (FERNANDES, 2000, p.23;32;33).

"Repetir, repetir - até ficar diferente" adverte em sua delicadeza e simplicidade nosso poeta Manoel de Barros (2009, p.11). Assim, é através do delineamento de uma performance iterável, de repetição e remetimento ao outro, que Bausch faz a tessitura de suas coreografias.

\section{PROVOCAÇÕES À FILOSOFIA}

Em seu movimento desconstrucionista, Derrida também se ocupou em pensar as Artes e, em entrevista (concedida à David Wills e Peter Brunette em 28 de abril de 1990 na Califórnia e publicada na obra coletiva 'Descontruction and the Visual Arts: Art, Media, Architecture'), ele questiona a supremacia do discurso filosófico em relação ao pensamento

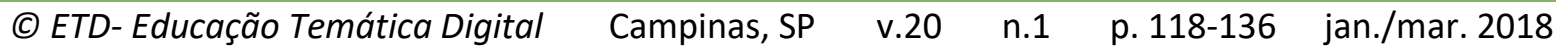


e argumenta que esse não é esgotado pela filosofia (2012); portanto, essa última é meramente uma forma de pensamento entre tantas outras. ${ }^{6}$

Com tal argumentação, Derrida reafirma sua convicção no tocante à impossibilidade de um (con)texto excluir outros contextos, bem como do (con)texto ser limitado, e assim, consequentemente, é que "Nunca podemos exaurir os cursos de um contexto" (Wolfreys, 2009 , p. 10). O olhar desconstrucionista derridiano não se alinha ao fechamento, à restrição de um único caminho a trilhar e nele se bastar.

“O pensamento não é exaurido pela filosofia" (2012, p.46),à essa afirmação contundente, Derrida ainda acrescenta que se interessa pelo pensamento, justamente quando esse excede a filosofia. E seguindo nessa direção, considera que existam "artes práticas de espaço que excedem a filosofia" (Ibid, p.46), e que ao interpelá-la, contrapõemse ao 'logocentrismo' filosófico - termo por ele utilizado para referir-se à centralidade do racional como verdade manifesta no discurso. Derrida observa que é por meio de suas criações que o/a artista questiona a filosofia. Assim, nessas 'artes práticas de espaço' se situa o pensamento que advém na experiência da obra. Dessa forma, há, inexoravelmente por parte da obra, uma provocação para pensar, já que o pensamento se encontra nela encarnado.

Na referida entrevista, Derrida esclarece ainda, que usa o termo 'artes espaciais' de uma forma estratégica, com a finalidade de associar essas artes ao texto, à noção de espaçamento, por meio da qual um elemento não significa, nem fornece sentidos, a menos que se remeta a outro elemento, por meio de uma economia de rastros (DERRIDA, 2001); de modo que, tais remetimentos findem por transpor as fronteiras de áreas comumente encasteladas em seus conhecimentos. É sob essa ideia, que Pina ao ser homenageada pela Universidade de Bolonha, em 1999, com o título de doutora honoris causa, relembrou que seus estudos - na escola 'Folkwangschule' em Essen(Alemanha), dirigida por Kurt Jooss, um dos fundadores da dança-teatro 'tanztheater' -, Ihe proporcionaram uma formação plural.

Em suas palavras:

\footnotetext{
${ }^{6}$ Similarmente, Gilles Deleuze e Félix Guattari ao questionarem a preeminência da filosofia sobre o pensamento, em 'Qu'est-ce que la philosophie?' - livro lançado em 1991 -, afirmam que à filosofia compete a invenção e a produção de conceitos, e essa exclusividade lhe atesta uma função, mas não uma prerrogativa, e nesse momento, aproximam-se da posição de Derrida ao observarem que "há outras maneiras de pensar" e também “de criar, outros modos de ideação que não têm de passar por conceitos (...)” (2010, p.15).
}

(C) ETD-Educação Temática Digital Campinas, SP $\quad$ v.20 $\quad$ n.1 $\quad$ p. 118-136 jan./mar. 2018


[...] havia tantas coisas a aprender, e todas despertavam a imaginação: a dança clássica e a moderna, o folclore europeu. Particularmente importante era que, na época, todas as seções ainda se achavam sob o mesmo teto: a música, a ópera, o teatro, a dança, fotógrafos, escultores, gráficos, designers de tecidos, tudo isso podia ser mutuamente desfrutado. E nada mais natural que se conhecesse de tudo um pouco. Desde então, não consigo ver sem espaço. Vejo também como um pintor ou fotógrafo vê. Essa visão espacial, por exemplo, é um componente bem importante de meu trabalho (BAUSCH, 2000 apud CYPRIANO, 2005, p. 24-25).

Multiplicidade de olhares, os quais propiciam uma produção inesgotável de significações outras. Transbordamento de possibilidades ao ultrapassar as fronteiras dos campos de atividades humanas. E, por esse viés, Pina Bausch também nos provoca com suas práticas artísticas, a pensar o corpo como campo de interdições, mas também de possibilidades ao desmonte da polarização que intenta enrijecer os corpos segundo uma lógica dual e hierarquizante.

Com tal proposta, seu pensamento nos remete mais uma vez a uma aproximação com as perspectivas derridianas ao conceber que toda estrutura conceitual é hierarquizante, e nela, alguns conceitos são superiores a outros, alguns centrais e outros periféricos, o que gera uma relação sempre conflituosa e tensionada. Em outras palavras, os processos de significação acontecem apoiados nesta lógica dualista que opõem os termos ao dispô-los nas extremidades da hierarquia. Tais procedimentos ocorrem por intermédio de relações de poder situadas nas práticas socioculturais, nas quais são demarcadas as posições dos sujeitos. Daí os binarismos: mente/corpo, homem/mulher, razão/emoção, masculino/feminino, palco/plateia, dentre tantos outros, findam por produzir relações assimetricamente demarcadas pelos termos situados em posição priviligiada.

Pina Bausch busca estremecer os discursos assentados nesse sistema rígido e polarizado que reforçam a dicotomia básica do masculino e feminino. Para tal intento, empenha-se em suas montagens, em romper com a naturalidade das oposições recorrendo amovimentos que têm por intenção o aprazimento das necessidades humanas. Dessa maneira, afagos acabam por se transformar em agressão, as investidas de um toque podem resultar em recusa. Pina busca mostrar as aparências e profundezas do ser humano, seus conflitos e desesperos. São corpos que densos de energia que podem se tornar delicados e vulneráveis nos encontros e desencontros (AZEVEDO, 2009).

Nesse contexto, os movimentos não se contrapõem nem completam as palavras, assim como o corpo não se contrapõe à mente, nem mesmo o completa. Nessa vertente, ela problematiza os limites impostos por uma suposta estrutura dada desde sempre e possibilita ao corpo que está no palco se deslocar para além das demarcações de um espaço circunscrito, e em '1980 - Ein Stück Von Pina Bausch' [1980 - Uma Peça de Pina Bausch], os criadores-bailarinos em trajes de festa, caminham por entre as fileiras, conversando e

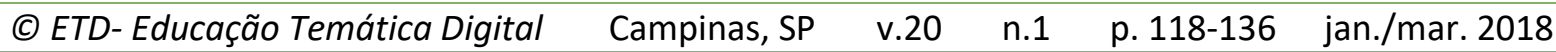


servindo chá ao público, movimentam-se e sentam-se na plateia. Invertem a hierarquia polarizada artista/espectador, provocando rupturas no espaço cênico.

Em 1979, num momento trágico da peça 'Arien' [Árias], um bailarino aparece no balcão do teatro, em meio à plateia, gritando que irá se jogar. Todo o elenco suplica para que ele não pule, e os espectadores se veem envolvidos em uma cena, cujas fronteiras entre realidade e ficção são muito tênues. Pina também transgride os limites colocados pela estrutura do teatro. Cypriano aponta, que quando Pina Bausch "subverte o local da encenação, ele já não pertence mais a nenhuma ordem" (2005, p.36). Neste sentido, entendemos que ao inverter a ordem polarizada do espaço da encenação, Pina a desloca para além da lógica dual e possibilita tanto aos criadores-bailarinos quanto aos expectadores, experiências vivenciadas em um espaço outro.

\section{MÚLTIPLOS OLHARES INCONCLUSOS}

Em 'Bandoneon' (1980), Pina Bausch rompe uma vez mais com as posições metafísicas ao mesmo tempo que questiona a essência dos gêneros ao colocar o dançarino Dominique Mercy se apresentando caracterizado de bailarina clássica. Assim, é colocado em cena, um corpo de homem, trajando um tutu romântico rosa - peça de figurino feminino do balé clássico, composto por um corpete justo e várias camadas de saia que se alongam até os joelhos -, cujo cenário é um salão de baile com enormes quadros de fotos de boxeadores.

Nesse trabalho, ela interpela o 'lugar' do feminino por meio de cenas compostas de tal forma, que não restringem a um único modo de ver. Em vez disso, os elementos que em um primeiro momento podem parecer contraditórios, findam por fornecer outros modos de leitura. Essa multiplicidade de olhares é propositalmente perseguida pela coreógrafa, que nos provoca: "você pode ver como 'isto ou como aquilo'. Apenas depende de como você assiste. Mas o pensamento unilateral com o qual se interpreta, simplesmente não está certo", e conclui, "você sempre pode assistir de outro modo" (HOGHE; TREE, 1980, p.73 grifos nossos). 


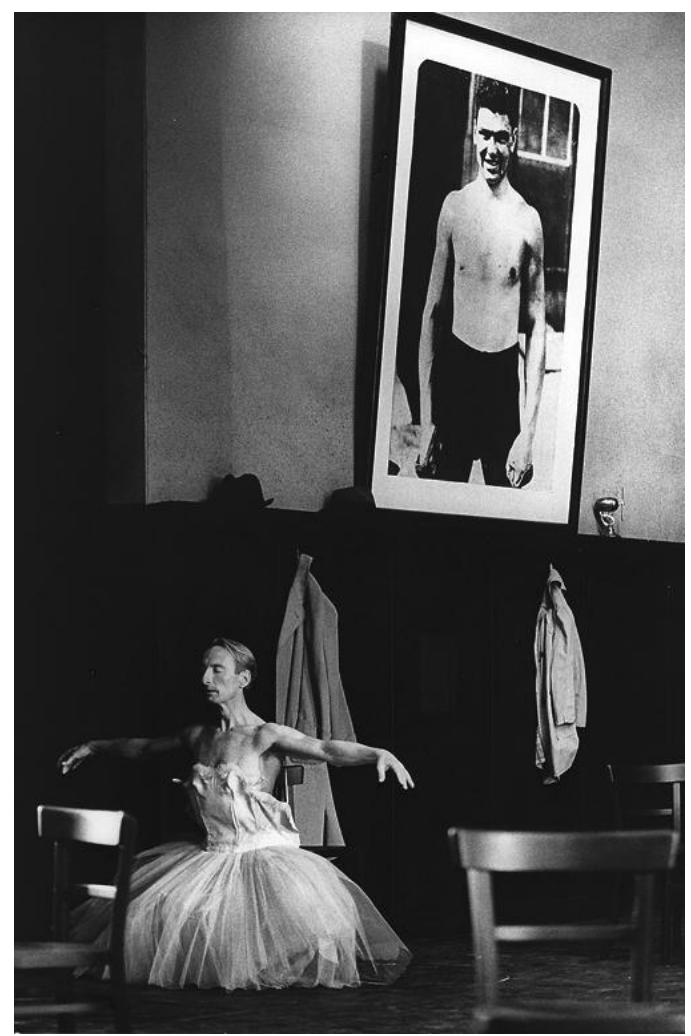

Imagem 4. Dominique Mercy - 'Bandoneon' - Foto: Ulli Weiss.

Ainda que a perspectiva em questão seja a problematização de uma visão exclusiva, em que Pina sugere um olhar flexível para que não se veja de uma única maneira, mas 'como isto ou como aquilo', atentamos para não nos enredarmos por entre vias que abalem o 'uno' e, entretanto permaneçam em uma lógica dual. Assim, consideramos também o pensamento do ni/ni, denominado por Cragnolini (2003) para aludir a um lugar indiscernível, que finda por posicionar os termos em um 'entre', nem isto e nem aquilo. Movimento que assusta, pois nos localiza em um 'não lugar'. Nem numa posição nem em outra, nem presença nem ausência, nem homem nem mulher, nem masculino nem feminino, todavia oscilando no 'entre'.

Esta oscilação do pensamento, denominada por Derrida de indecibilidade, aponta para uma dinâmica que opõe resistência à lógica binária da metafisica. Se essa implica a posição dos termos em uma das extremidades, os indecidíveis os lançam para um não lugar. Para o filósofo franco-argelino, os indecidíveis nos remetem a uma questão com múltiplas implicações em vez de oposições que claramente definem que "eu sou isto ou aquilo. Não, eu sou isto e aquilo; e sou antes isto que aquilo, de acordo com as situações e as urgências" (DERRIDA, 2004a, p.35), enviando-nos desta maneira a uma gramática localizada e idiossincrática. Logo, em vez da redução a um único significado, conforme Pina problematiza, esse movimento torna "indecidível o significado unívoco" (WOLFREYS, 2009, p.54).

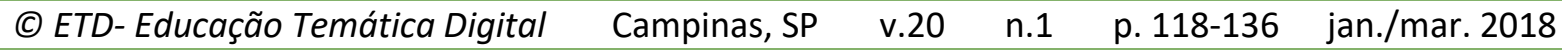


Assim sendo, a atuação da personagem de Dominique Mercy é marcada pela problematização de um 'eu' que ao mesmo tempo é outro, tantos outros... Na intensidade do corpo em cena, a descentralização do 'eu' faculta a desconstrução de diferenças hierarquizadas entre o masculino e o feminino localizados em espaços tão bem demarcados pela lógica falocêntrica. ${ }^{7}$

Ao mobilizar grandes plateias ao redor do mundo através de suas peças que problematizam a condição humana, provocando olhares diversos às relações entre as pessoas, explorando gestos e movimentos que desestabilizam a dicotomia hierarquizante que posiciona homens e mulheres, Pina Bausch inscreve sua obra para além da lógica binária. Lógica essa, que segundo Derrida, insiste em governar "o decoro de todos os códigos, além da oposição feminino/masculino" (DERRIDA, 1982, p.108, tradução nossa). ${ }^{8}$

Ela, bailarina e coreógrafa, parece compartilhar o sonho do filósofo no qual a "coreografia pode transportar, dividir, multiplicar o corpo de cada 'indivíduo'" (DERRIDA, 1982, p.108, tradução nossa) ${ }^{9}$ ao acolher as inúmeras vozes, todas elas misturadas e cujas marcas sexuais não são identificadas.

\section{REFERÊNCIAS}

ALMEIDA, Marcia Furlan de. Os incalculáveis usos do feminino e do masculino em jogos de linguagens. Texto de qualificação aprovado. Programa de Pós-Graduação em Educação, Universidade Estadual de Campinas, 2014. Mimeo.

AZEVEDO, Sonia Machado de. O papel do corpo no corpo do ator. São Paulo: Perspectiva, 2009.

BARROS, Manoel de. O livro das ignorãças. 16 ed. Rio de Janeiro: Record, 2009.

BAUSCH, Pina. Dance, ou estamos perdidos. Caderno Mais, Jornal Folha de São Paulo, São Paulo, 27 ago. 2000. Disponível em:

http://www1.folha.uol.com.br/fsp/mais/fs2708200008.htm. Acesso em: 15 out. 2015.

BONDIA, Jorge Larrosa. Notas sobre a experiência e o saber da experiência. Revista

Brasileira de Educação, n. 19, p. 20-28, jan. fev. mar. abr. 2002.

\footnotetext{
${ }^{7}$ Falocentrismo é um neologismo criado por Jacques Derrida para problematizar a ideia de superioridade do masculino em relação ao feminino, baseada no falo.

${ }^{8}$ Excerto da entrevista de Jacques Derrida à Christie V. McDonald. No original: “(...) The relationonship would not be a-sexual, far from it, but would be sexual otherwise: beyond the binary difference that governs the decorum of all codes, beyond the opposition feminine/masculine, (...)".

${ }^{9}$ Excerto da mesma entrevista citada em nota anterior. No original: "I would like to believe in the masses, this indeterminable number of blended voices, this mobile of non-identified sexual marks whose choreography can carry, divide, multiply the body of each "individual," whether he be classified as "man" or as "woman" according to the criteria of usage".
}

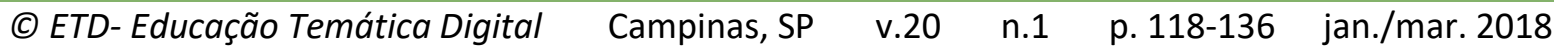


BONDIA, Jorge Larrosa. Experiência e Alteridade em Educação. Tradução Maria Carmen Silveira Barbosa; Susana Beatriz Fernandes. Revista Reflexão e Ação, Santa Cruz do Sul, v.19, n. 2, p. 04-27, jul./ dez. 2011.

CANELAS, Lucinda. Por dentro todos temos a mesma linguagem. Jornal de Lisboa, Lisboa, 03 jan. 2003.

CRAGNOLINI, Mónica B. Temblores del pensar: Nietzsche, Blanchot, Derrida. Pensamiento de los Confines, Buenos Aires, n.12, jun. 2002, p. 111-119. Disponível em:

http://www.jacquesderrida.com.ar/comentarios/temblores.htm Acesso em: 30 jan. 2013.

CORBIN, Alain; COURTINE, Jean-Jacques; VIGARELLO Georges. História do corpo: da Renascença às Luzes. Tradução Lúcia M. E. Orth. Petrópolis: Vozes, 2008.

CYPRIANO, Fabio. Pina Bausch. São Paulo: Cosac Naify, 2005.

DERRIDA, Jacques. Choréographies: entrevista com Christie V. McDonald. In: DERRIDA, Jacques.Points de suspension:entretiens. Coautoria de Elisabeth Weber. Paris: Galilée, 1992.

DERRIDA, Jacques; ROUDINESCO, Elisabeth. De que amanhã: diálogo. Tradução André Telles. Rio de Janeiro: Jorge Zahar, 2004a.

DERRIDA, Jacques. Papel-máquina. Tradução Evandro Nascimento. São Paulo: Estação Liberdade, 2004b.

DERRIDA, Jacques. As artes espaciais: uma entrevista com Jacques Derrida. In: Pensar em não ver: escritos sobre as artes do visível (1979-2004). Tradução Marcelo Jacques de Moraes. Florianópolis: Editora UFSC, 2012.

DERRIDA, Jacques. Posições. Tradução Tomaz Tadeu da Silva. Belo Horizonte: Autêntica, 2001.

FERNANDES, Ciane.Pina Bausch e o Wuppertal dança-teatro: repetição e transformação. São Paulo: Hucitec, 2000.

GARAUDY, Roger. Dançar a vida. Tradução Antonio Guimarães Filho. Rio de Janeiro: Nova Fronteira, 1980.

GALLO, Sílvio. Eu, o outro e tantos outros: educação, alteridade e filosofia da diferença. Anais do II Congresso Internacional Cotidiano: Diálogos sobre Diálogos, Universidade Federal Fluminense, Niterói, 2008.

GIL, José. Movimento total: o corpo e a dança. Tradução Miguel Serras Pereira. São Paulo, SP: Iluminuras, 2004.

GUERREIRO, Mônica. Uma conversa com Pina Bausch. Obscena: revista de artes performativas, Portugal, n. 4, 2007, p. 60-69.

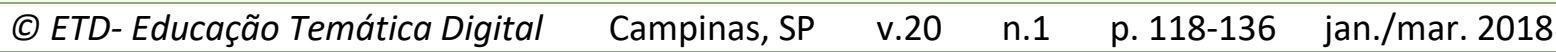


HOGHE, Raimund; TREE, Stephen. The Theatre of Pina Bausch. The Drama Review German Theatre Issue, v. 24, n. 1, p.63-74, mar. 1980.

KATZ, Helena. Pina Bausch coreografa seu conceito de cidade. 0 estado de São Paulo, São Paulo, 14 dez. 2000. Disponível em:

http://www.helenakatz.pro.br/midia/helenakatz61218723376.jpg Acesso em: 21 nov. 2015

NAVAS, Cássia Alves de Castro. Interdisciplinariedade e intradisciplinariedade em dança. Seminários de Dança I - História em Movimento: biografias e registros em dança. Joinville, Festival de dança, 2008.

PORTINARI, Maribel. Nos passos da dança.Rio de Janeiro: Nova Fronteira, 1985.

WEISS, Ulli; HOGHE, Raimund. Bandoneon: em que o tango pode ser bom para tudo?. São Paulo: Attar, 1989.

WOLFREYS, Julian. Compreender Derrida. Tradução Caesar Souza. 2. ed. Petrópolis: Vozes, 2009.

\section{Documentos Fílmicos}

BAUSCH, Pina. Árias [Arien]. Alemanha. Acervo São Paulo: Instituto de Artes Unicamp, 1 DVD, 150 min., 1985.

BAUSCH, Pina. 1980 - Uma peça de Pina Bausch [1980 - Ein Stück Von Pina

Bausch].Alemanha. Acervo São Paulo: Instituto de Artes Unicamp, 1 DVD, 128 min., 1980.

BAUSCH, Pina. O que Pina e seus dançarinos fazem em Wuppertal. Alemanha. Acervo São Paulo: Instituto de Artes Unicamp, 1 DVD, 115 min., 1982.

BAUSCH, Pina. Café Müller. Alemanha. Acervo São Paulo: Instituto de Artes Unicamp, 1 DVD, 48 min., 1978.

BAUSCH, Pina. Sonhos em Movimento [Tanzträume]. Direção Anne Linsel, Rainer Hoffmann. Alemanha. Duração 89 min., 2010.

\footnotetext{
'Revisão gramatical do texto sob a responsabilidade de: Lia Nogueira Marques. Email: lianogueiramarques@gmail.com
} 